\title{
AS IMAGENS PUBLICITÁRIAS NO LIVRO DIDÁTICO DE GEOGRAFIA: UMA LEITURA VISUAL A PARTIR DO MÓDULO 5 DO 8 ANO DO PROJETO RADIX
}

\author{
Valéria Nancí de Macêdo Santana ${ }^{1}$ \\ Simone Santos de Oliveira ${ }^{2}$
}

\begin{abstract}
Resumo: No contexto atual, o da contemporaneidade, é indiscutível o lugar que a imagem ocupa no mundo, uma vez que ela está presente em todas as atividades que desenvolvemos, quer fora quer dentro dos espaços escolares. Este estudo traz uma breve análise das imagens publicitárias utilizadas pelos autores Valquíria Pires e Beluce Belucci, no módulo 5 do livro didático de Geografia do Projeto Radix, do 8o ano do Ensino Fundamental II, da editora Scipione, tendo como objetivo principal compreender como as imagens publicitárias são colocadas neste importante recurso didático. Ao mesmo tempo, julgamos oportuno e instigante investigar como o consumo e o consumismo são retratados através das mensagens trazidas pela publicidade e propaganda no referido livro didático.

Palavras-Chave: Imagens publicitárias, Livro didático de geografia, Projeto Radix.
\end{abstract}

\begin{abstract}
In the current context, the contemporaneity, the place is undisputed that the picture fills the world, since it is present in all the activities we developed, either within or outside the school premises. This study provides a brief analysis of advertising images used by the authors Valkyrie Pires and Beluce Belucci, Module 5 of the textbook Geography Project Radix, the 8th year of elementary school II, published by Scipione, having as main objective to understand how images advertising is placed on this important teaching resource. At the same time, we believe timely and provocative investigate how consumption and consumerism are portrayed through the messages brought by publicity and propaganda in that textbook.
\end{abstract}

Keywords: Advertising images, Textbook of geography, Radix Project.

1 Licenciada em Geografia pela UEFS; Bacharel em Comunicação Social com Habilitação em Publicidade e Propaganda pela Unidade de Ensino Superior de Feira de Santana; Pósgraduada em Métodos e Técnicas de Ensino pela Universidade Salgado de Oliveira (RJ); Pós-Graduanda em Formação Continuada em Mídias na Educação pela Universidade Estadual do Sudoeste da Bahia (UESB); Mestranda no Programa de Pós-Graduação em Desenho, Cultura e Interatividade (PPGDCl/UEFS); professora de Geografia pela Secretaria de Educação do Estado da Bahia. Endereço eletrônico: valeriananci@ig.com.br.

Doutoranda no Programa de Pós-graduação em Educação e Contemporaneidade, da Universidade do Estado da Bahia (PPGEduC/UNEB/Campus I, Salvador), sob orientação do professor Dr. Elizeu Clementino de Souza; Mestre pelo Programa de Pós-Graduação em Desenho, Cultura e Interatividade (PPGDCI/UEFS); Professora Assistente de Prática de Ensino e Estágio Supervisionado em Geografia no Departamento de Educação da UNEB/Campus XI, Serrinha. Endereço eletrônico: ssoliveira_valentec3@yahoo.com.br. 


\section{COMPREENDENDO A PROPOSTA DOS AUTORES NO PROJETO RADIX: UMA INTRODUÇÃO}

O livro de Geografia do 8o ano do Ensino Fundamental, publicado pela editora Scipione, nos convida a fazer uma reflexão sobre a geografia escolar, no que concerne aos mais diversos assuntos, dados e fenômenos da natureza geográfica, ao abordar desde assuntos relacionados aos conceitos das principais categorias espaciais, como lugar, paisagem e espaço geográfico até temáticas ligadas ao consumo e consumismo, sobretudo expressas nas variadas imagens impressas no módulo 5 do livro didático do Projeto Radix.

Vale ressaltar que os livros didáticos têm se inserido na tecnologia cultural, ao colocar em suas páginas uma quantidade expressiva de imagens que retratam o meio técnico científico informacional. Tal situação revela que a imagem é elemento predominante e evidencia que atualmente esse tipo de livro, qual seja, o didático, deixou a cultura escrita para trás, entrando na nova era, centrada no uso da imagem.

Além da grande variedade de uso de imagens, este recurso didático nos convida à reflexão visual e interpretativa de algo que, durante muito tempo, fora relegado a segundo plano: a leitura e compreensão imagética, gerando, assim, uma maior socialização da apreensão do estudo da Geografia, uma vez que as imagens provocam pensamentos e podem ser consideradas textos imagéticos.

Vale salientar que esta obra didática traz como proposta a integração do conhecimento geográfico e a realidade do aluno, enfatizando a interdisciplinaridade, considerada tão importante no âmbito da realização das atividades e aprendizagens escolares. Para tanto, traz mapas, um caderno de atividades, fotos de satélites, sugestões de atividades e programas disponibilizados pela internet, além dos acidentes geográficos e a questão do consumo e do consumismo, considerados características marcantes do atual estágio pelo qual a nossa sociedade está passando.

\section{ENTRE O VISÍVEL, O ILUSÓRIO... A IMAGEM NOS LIVROS DIDÁTICOS DE GEOGRAFIA}

As imagens acompanham a trajetória humana há muito tempo, como bem testemunham as pinturas rupestres, presentes nas paredes rochosas 184 Número temático: Desenho e Educação: Cultura Visual e Cidade. A Cor das Letras - UEFS, n. 
em diferentes lugares do mundo. Depois delas, o nosso imaginário materializou-se em diferentes tipos de produção pictórica, até alcançarmos a sofisticação da pintura renascentista.

O termo imagem é tão utilizado, com tantos tipos de significação sem vínculo aparente, pois, muitas vezes, parece-nos bem difícil dar uma definição simples para ela que recubra todos os seus empregos. Entretanto, no campo da arte, a noção de imagem "vincula-se essencialmente à representação visual: afrescos, pinturas, mas também iluminuras, ilustrações decorativas, desenho, gravura, filmes, vídeo, fotografia e até imagens de síntese" (JOLY, 1996, p. 18).

Cotidianamente, hoje utilizamos a palavra imagem para caracterizar o que vemos na tela da televisão, do computador, o que os nossos olhos detectam numa caminhada pela cidade, o que encontramos ao abrir muitos dos livros que são comercializados na contemporaneidade, pois os livros didáticos podem ser considerados como recursos de ensino e de aprendizagem mais universal, existente na cultura escolar, sendo valorizado desde a escola tradicional, ora usado como texto nas aulas, ora servindo de consulta para os professores ministrarem suas aulas, estando sempre presentes nas práticas escolares, mesmo atravessando mudanças metodológicas nas práticas pedagógicas vivenciadas no âmbito escolar.

Vivemos numa cultura da imagem, ora expressada pela mídia, pelas propagandas nos outdoors ${ }^{3}$, ora presentes nos livros didáticos, embora, diversas vezes, fazendo-se despercebidas por muitos dos profissionais que atuam na educação.

Temos percebido que vários artistas têm certa resistência em utilizar a palavra imagem, preferindo usar a generalização técnica para tratar de suas produções, como "pinturas", "esculturas", "gravuras" e assim por diante. Infelizmente, a palavra imagem tem sido utilizada somente para se referir à fotografia, ao cinema, ao computador e à TV. A semiótica prefere ampliar o termo e falar em imagem como resultado de algo gerado pelo campo visual.

Mesmo que a produção de imagens tenha acompanhado o processo civilizatório, registrando nelas os medos, as conquistas, as aspirações de sociedade, grupos e indivíduos, as relações com a produção visual nem sempre foram tranquilas, sobretudo às ocidentais, uma vez que as socieda-

3 Considerado um dos grandes meios publicitários exteriores, sobretudo nas placas modulares dispostas em locais de grande visibilidade, como em ruas, avenidas, rodovias ou nas empenas de edifícios nos médios e grandes centros urbanos. 
des orientais sempre foram marcadas pela diversidade de valores, sendo muitas vezes mais receptivas à imagem, pois os ocidentais, herdeiros dos socráticos, teriam centralizado os seus valores no único Deus, tão defendido pelo catolicismo, como afirma Durand (1998).

Corroboramos com Joly (1996) ao afirmar que a imagem é:

Instrumento de comunicação [...], assemelha-se ou confunde-se com o que representa. Visualmente imitadora, pode enganar ou educar. Reflexo, pode levar ao conhecimento. A Sobrevivência, o Sagrado, a Morte, o Saber, a Verdade, a Arte, se tivermos um mínimo de memória, são os campos a que o simples termo "imagem" nos vincula. Consciente ou não, essa história nos constituiu e nos convida a abordar a imagem de uma maneira complexa, a atribuir-lhe espontaneamente poderes mágicos, vinculada a todos os nossos grandes mitos (JOLY, 1996, p. 19).

Nos livros didáticos, a imagem é um elemento visual extremamente importante e merece destaque pelos sujeitos que os utilizam, uma vez que "a imagem faz com que as palavras percam sua mobilidade e intermutabilidade", como afirma Paz (1982, p. 135), pois elas falam por si, devendo ser exploradas mais significativamente pelo professor, sobretudo quem ensina Geografia, devendo este ensino deter-se desta nova cultura imagética, na tentativa de desenvolver uma pedagogia mais preocupada com a leitura de imagens inscritas nos livros didáticos, pois ler imagens criticamente significa aprender a apreciar, a decodificar e interpretar também fatos geográficos, numa perspectiva também de letramento geográfico, tão bem colocado por Castellar (2011) quando discute a cartografia escolar como um sistemacódigo de comunicação imprescindível para o processo de aprendizagem geográfica.

Tonini (2011), ao discutir a imagem como potência educativa, afirma que vários estudos colocam a imagem, como constituidora do real, se tornaram centrais nos últimos anos, principalmente a partir dos novos entendimentos ao colocar que as imagens são mais do que uma forma de linguagem, como meio de comunicação, elas são mais do que isso. Portanto, elas imprimem significados às nossas vidas, ao alimentar as nossas subjetividades, uma vez que elas podem influenciar nos nossos modos de pensar e agir no espaço geográfico, podendo ser percebidas tanto como práticas discursivas (signos de uma linguagem) como também objetos do mundo (obras da/ na cultura). Sobre esta discussão, esta autora coloca que se faz necessário: 
Entender a imagem como um discurso, um elemento disciplinar que tenta fixar um determinado significado como natural. Dessa maneira, tornam-se tão relevantes as indagações iniciais sobre o que se está vendo com o que está sendo produzido como conhecimento na imagem (TONINI, 2011, p. 152).

Além do discurso trazido pelas imagens que acabam se entrelaçando aos nossos, através do invisível, do ilusório, as imagens contidas nos livros didáticos nos fazem adquirir também novos valores e atitudes, ensinandonos a ter outra visão de mundo e aceitarmos outros comportamentos sociais e econômicos, ora colocados, muitas vezes, como verdades, vai nos moldando, constituindo as nossas subjetividades, uma vez que elas são consideradas como veículos de mensagens simbólicas, pois as imagens constroem significados e os transmitem, caracterizados como meios que carregam significação por funcionarem como símbolos que transmitem significados ou representam o que desejamos comunicar.

\section{MENSAGENS PUBLICITÁRIAS EM LIVROS DIDÁTICOS: O VISUAL QUE INFLUENCIA}

Falar de mensagem publicitária contidas nos livros didáticos é nos remeter a uma realidade cada vez mais presente, uma vez que reflete as mudanças e transformações ocorridas nas sociedades, resultantes do processo de globalização que impõe aos sujeitos de uma dada sociedade, independentemente de sua cultura, de seus valores e crenças, o ato de consumir os mais diversos produtos, promovendo o consumismo através da publicidade e da propaganda.

Sobre os conceitos de publicidade e de propaganda, Sandmann (2001) assim coloca:

Em português publicidade é usado para a venda de produtos ou serviços e propaganda tanto para propagação de ideias como no sentido de publicidade. Propaganda é, portanto, o termo mais abrangente e o que pode ser usado em todos os sentidos (SANDMANN, 2001, p. 10).

As mensagens publicitárias de cunho visuais são impactantes e, por sua força, determinantes na decisão da compra, provocado por impulso. Muitas vezes, tais mensagens são entendidas como manipuladoras, pois "a propaganda e a publicidade têm por objetivo modificar a conduta das pessoas por meio da persuasão, quer dizer, sem parecer obrigá-las" (DURANDIN, 1997, p. 13). 
No geral, nos livros didáticos, sejam eles de História, Português, Matemática, Geografia, dentre outros, a publicidade está sempre presente, sobretudo, quando se refere aos assuntos que abrangem relevância mercadológica. Mas, como para tudo há uma explicação, autores e editoras buscam explicitar tais motivos, colocando que utilizam anúncios publicitários nos livros didáticos com o intuito de "[...] aproximar a educação formal do cotidiano dos adolescentes" (BACCEGA, 2007, p. 85).

Sobre esta questão, faz-se necessário discutirmos um pouco sobre o que vem sendo matéria nos jornais do Chile, no que concerne às discussões sobre os livros didáticos.

Nas páginas online do Estadão do dia 10 de abril de 2011 está estampada a seguinte notícia: "Chile põe publicidade em livro didático: alunos de escolas privadas leem diariamente anúncios sobre as vantagens de ter determinados produtos; medida causa polêmica" ${ }^{4}$. A reportagem coloca que entre uma lição e outra, há propagandas dispostas em páginas inteiras, sendo lidas diariamente por milhares de crianças menores de 12 anos de idade, incentivando esses estudantes a consumirem os produtos ora anunciados. Tal problemática levou os pais, educadores e autoridades a realizarem um debate nacional sobre essa questão.

O fato é que no Chile os livros didáticos, diferentemente do módulo 5, do livro de Geografia do Projeto Radix - 8 ano, instigam e aguçam nas crianças, que os folheiam, a consumir. O cuidado, retratado no livro que é o nosso objeto de estudo, em não incitar o consumismo no leitor da obra, não é visto nos livros didáticos do Chile, como é sinalizado neste excerto da matéria:

A estudante María Jesús Manosalva, de 11 anos, estuda em uma das escolas mais tradicionais da cidade de Temuco, no sul do Chile. Em seu livro de espanhol há duas propagandas de empresas privadas que ocupam quase meia página cada uma (CHARLEAUX, 2011a).

Charleaux (2011a) ainda afirma que todas as crianças do Chile são consumidoras dos produtos anunciados nos seus livros. Tal afirmativa é retratada no excerto narrativo da mesma estudante chilena de 11 anos de idade, a do fragmento acima, ao narrar que "Os anúncios são bonitos, coloridos e fáceis de decorar. Eles ficam na cabeça. Eu gosto deles".

4 Matéria disponibilizada no site http://www.estadao.com.br/estadaodehoje/20110410/ not_imp704193,0.php.

188 Número temático: Desenho e Educação: Cultura Visual e Cidade. A Cor das Letras - UEFS, $n$. 
O debate promovido pelos pais, educadores e autoridades chilenas é muito importante, ao enfatizar até que ponto, afinal, os anúncios publicitários devem fazer parte da vida diária de um aluno em sala de aula. Tal situação nos aguça com os seguintes questionamentos: Deve fazer parte? De que modo?

O problema não é a publicidade em si, mas sim, a forma abrupta como esta é levada aos estudantes chilenos. Nessa mesma matéria, Charleaux (2011a), no Estadão online, complementa:

Em livros de espanhol, sites de empresas privadas aparecem como
"sugestões complementares de leitura". Os estudantes também veem
banners, logotipos, embalagens, jingles e outras peças publicitárias dirigidas
justamente às crianças, um público conhecido por seu apetite voraz de
consumo e pelo poder de persuasão diante dos pais. Num dos livros, o
enunciado convida o estudante a cantar: "Meu primeiro Claro (celular) é a
forma mais legal de falar com meus amigos." O conteúdo - difundido pela
empresa no último Dia das Crianças - é apresentado a alunos da 5. a série
em um livro de Linguagem e Comunicação de uma das maiores editoras do
Chile, a Santillana (CHARLEAUX, 2011a).

Vale ressaltar que crianças de 5a série/6으 Ano do Ensino Fundamental são altamente influenciáveis, sobretudo pelo fato de estarem em fase de formação intelectual e de identidade. O poder imagético das imagens, da linguagem visual que a publicidade proporciona, gera a persuasão. Se em adulto isso é frequente, que dirá em crianças.

Em contrapartida, nesta mesma matéria de Charleaux (2011a) no referido jornal, é mencionado "o valor educativo da publicidade", enfatizado pelo ministro da educação do Chile, ao colocar que:

[...] defendo o valor educativo dos textos publicitários, mas, diante das crescentes reclamações de pais e professores, começou a admitir pela primeira que talvez a iniciativa tenha ido longe demais. As editoras garantem que não recebem por divulgar os anúncios. Pelo contrário, pedem autorização às empresas (Ministro de Educação do Chile in CHARLEAUX, 2011a).

Há editoras que se defendem, trazendo para o debate o fato de não receber pelos anúncios, logo, tentando deixar claro não agir com a má fé, como é colocada por Carmem Ureña, vice diretora da editora Santillana (apud CHARLEAUX, 2011a), ao dizer que "a utilização de marcas reais nos textos de Linguagem e Comunicação não constitui de forma alguma publicidade porque a editora não recebe dinheiro dessas empresas para que figurem no material pedagógico". 
Mas há um aspecto intrigante e, ao mesmo tempo, interessante para refletirmos a partir desta matéria do Estadão ao apontar para um fato importante em relação à utilização das propagandas nos livros didáticos, ao colocar que a ideia é fazer crianças entenderem melhor a publicidade real, colocada pelo ministro da Educação do Chile, Joaquín Lavín (apud CHARLEAUX, 2011a), defendendo que as propagandas pretendem somente "fazer com que as crianças enfrentem melhor a publicidade a qual estão expostas todos os dias, nas ruas e na televisão" Será que, de fato, é essa a intenção? Claro que não!

$\mathrm{E}$, ao fim desta citada matéria do Estadão, surge um novo item a ser pensado: propaganda fictícia $x$ real nos livros didáticos, quando Charleaux (2011a) coloca que Lavín, ministro da educação do Chile, reconhece que as peças publicitárias deveriam ser fictícias, para que as crianças aprendessem sobre propaganda sem que fossem expostas a uma marca determinada.

\section{CONSUMO E CONSUMISMO EM IMAGEM: LEITURA IMAGÉTICA DO MÓDULO 5 DO LIVRO DE GEOGRAFIA DO PROJETO RADIX - 8 ANO}

Quando se objetiva retratar um determinado assunto numa obra como é o livro didático, alguns aspectos são relevantes para o alcance daquilo que se almeja. Estamos, pois, falando da produção de um livro didático, do cuidado em pensá-lo e executá-lo. Com efeito, cabe-nos pontuar a importância de se observar o público-alvo do mesmo.

Neste caso específico, nos utilizamos da análise do livro de Geografia - Projeto Radix - 8o ano, especificamente do módulo 5, pelo fato do mesmo trazer como subtítulo o consumo e o consumismo, assuntos dos quais a imagem se faz de extrema importância.

Este tipo de conteúdo, qual seja, consumo e/ou consumismo, é, muitas vezes, desvelado a partir do uso de imagens, fazendo emergir um seguinte questionamento bastante pertinente dentro do contexto atual que vivemos, onde cada vez mais percebemos a necessidade de trabalhar com as crianças e jovens a questão do meio ambiente, da poluição, do desperdício, do lixo e do consumo exagerado, levando-nos a pensar sobre: como tratar a questão das imagens que enfatizam o consumo e do consumismo, empreendidas, de modo, muitas vezes, subliminar, pela publicidade e da propaganda nos livros didáticos, de modo coerente para adolescentes do ensino fundamental, sem influenciá-los de modo negativo? 
Os autores, Valquíria Pires e Beluce Belucci (2009), do módulo 5, do livro didático de Geografia do Projeto Radix, do 8 o ano do ensino fundamental, da editora Scipione, tiveram o cuidado e o trato de trabalhar o assunto mencionado, em forma de desenhos, sem se utilizar de mensagens publicitárias reais (escritas e/ou imagens reais) que pudessem vir a incitar a compra de algum produto específico, o que fica claro na dica que os mesmos deixaram aos professores na legenda ao lado da Figura 1, ao dizerem que consultem a sugestão contida no quadro proposto pela assessoria pedagógica para evitar o consumismo.

Figura $1-O$ consumo

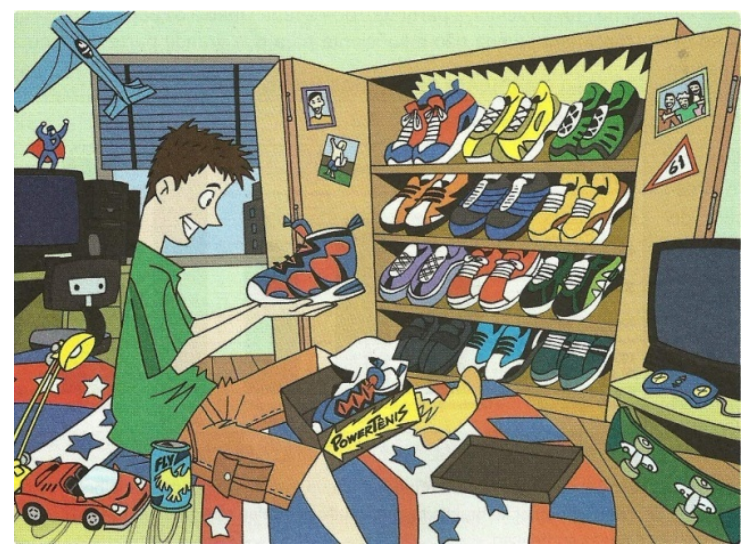

Fonte: Gustavo Machado (apud PIRES e BELUCCI, 2009, p. 98).

Na mesma Figura 1, os autores também se dirigem aos alunos, ao colocarem que "muitas vezes, estimulados por anúncios publicitários, adquirimos produtos sem realmente necessitar deles" (PIRES, BELUCCI, 2009, p. 98).

Já na página seguinte do livro didático, ora abordado, é colocada uma mensagem aos professores enfatizando que a fotografia da Figura 2 foi colocada de modo proposital, de finalidade didática, uma vez que Juca Varela, autor da imagem/fotografia, teve o devido cuidado de não retratar nenhuma empresa ou marca dos produtos visualizados na fotografia, não incentivando os estudantes ou qualquer que seja, a comprá-los. Além dessas, outras imagens também são colocadas e, de certa forma, não excitam imediatamente a compra porque não evidenciam a marca do produto. 
Figura 2 - Produtos comercializados

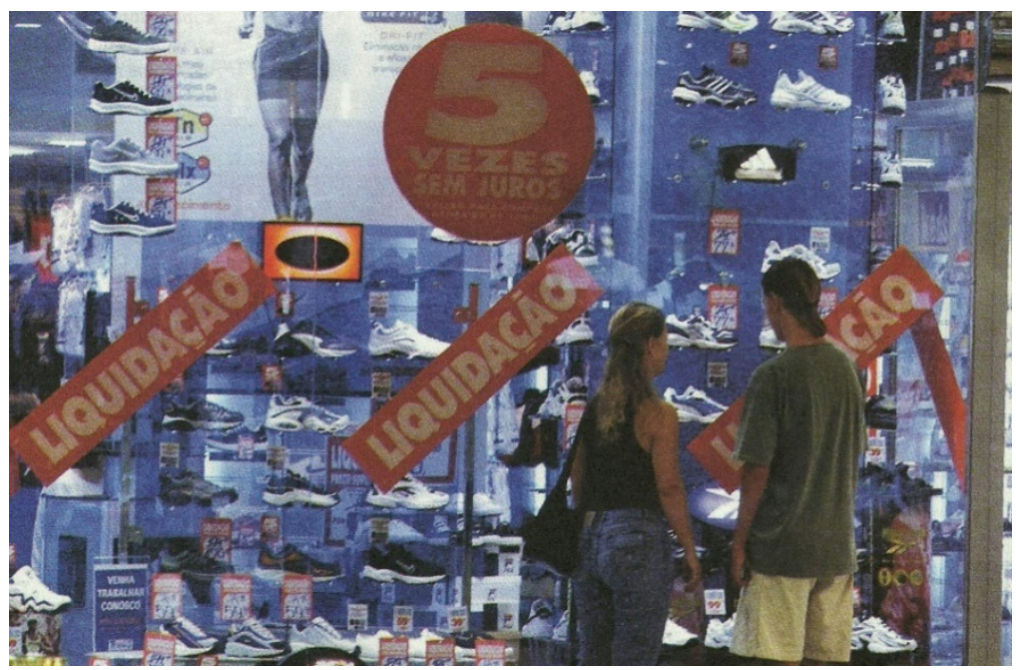

Fonte: Juca Varella (apud PIRES e BELUCCI, 2009, p. 99).

E, abaixo desta Figura 2, no livro didático, os alunos se deparam com a seguinte citação:

Muitas lojas estampam nas vitrinas a liquidação de seus produtos. Essas promoções, na maioria das vezes, atraem o interesse do consumidor, incentivando-o a entrar na loja e a adquirir alguma mercadoria. Na imagem acima, observamos a vitrina de uma loja de tênis promovendo uma liquidação (PIRES, BELUCCI, 2009, p. 99).

Sequencialmente, na página 100 , desta mesma obra, encontramos a seguinte figura: 
Figura 3 - Anúncio e realidade

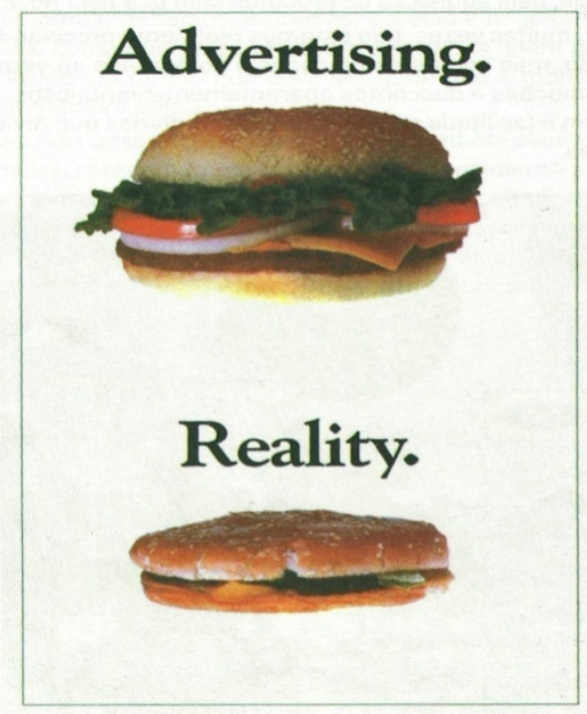

Fonte: Kupstas (apud PIRES e BELUCCI, 2009, p. 100).

Ao lado esquerdo da peça publicitária, da Figura 3, nos deparamos com uma mensagem direcionada aos educadores, informando que "algumas peças publicitárias foram reproduzidas propositadamente com a finalidade didática, porém, com o devido cuidado autoral de não recomendar qualquer tipo de produto ou empresa nesta e nas demais imagens do livro" (PIRES; BELUCCI, 2009, p. 100).

Vale ressaltar que ao lado direito da imagem da Figura 3, há uma mensagem para os educandos, informando que nesta, as autoras fazem uma crítica a alguns tipos de anúncios publicitários que anunciam um produto supervalorizando qualidades que, muitas vezes, ele não possui.

E, por fim, na página 104, neste livro didático, em análise, encontramos um anúncio de veículo (Figura 4), com uma informação para os professores dizendo que algumas peças publicitárias foram reproduzidas propositadamente com a finalidade didática, porém, com o devido cuidado autoral de não recomendar qualquer tipo de produto ou empresa nesta e nas demais imagens do livro. 
Figura 4 - Automóvel fabricado na década de 1940

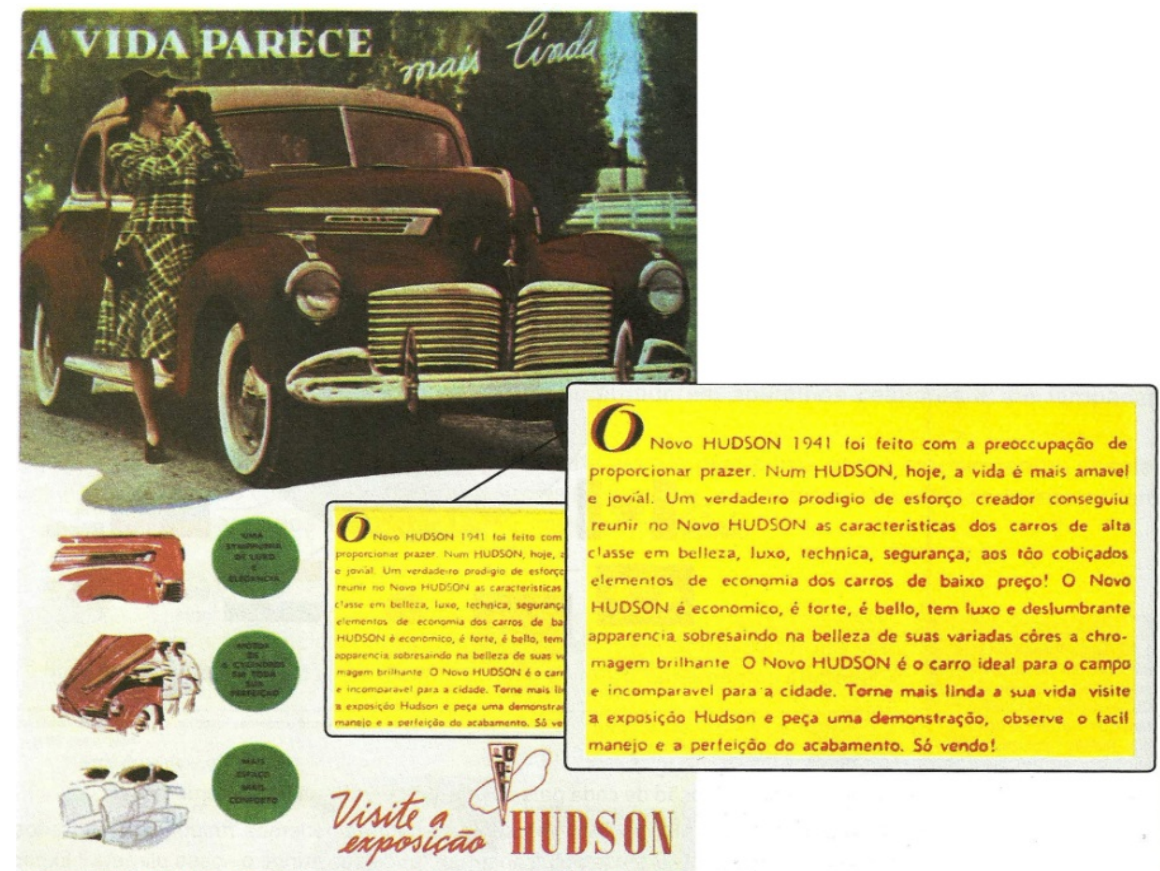

COMPANHIA COMMERCIAL E MARITIMA

Fonte: Revista O Cruzeiro, Rio de Janeiro, 8 fev. 1941 (apud PIRES e BELUCCI, 2009, p. 104).

Diante dessas e de outras imagens publicitárias, ainda fica o questionamento sobre até que ponto a utilização do uso das mesmas, sobretudo de produtos de bens de consumo duráveis e não duráveis, de marcas conhecidas num livro didático, pode influenciar a compra desenfreada de tais produtos? Será que educação e negócios deverão estar sempre associados, sobretudo no que concerne à utilização das imagens nos livros didáticos?

Bem, muitas perguntas ficam sem respostas, mas o fato é que "O livro didático, ao reproduzir um anúncio publicitário, deveria se empenhar também na construção do cidadão crítico", afirma Baccega (2007, p. 90).

O jornal Estadão de 11 de abril de 2011 trouxe mais debates sobre a publicidade nos livros didáticos tratando do possível negócio em que se transformou a educação chilena. Esta edição começou da seguinte forma: "Além das implicações pedagógicas, a mistura entre empresas privadas e 
educação provocou um questionamento estrutural: até onde essa relação é sadia?" (CHARLEAUX, 2011b).

A preocupação da sociedade desse país com tal temática tornou-se tão imediata naquele período que diversos políticos deram suas opiniões sobre a mesma, colocando que "Está ficando cada vez mais claro, no Chile, que a educação é um negócio", afirma a deputada de oposição Cristina Girardi, na matéria organizada por Charleaux (2011b).

Na citação posterior, ainda pode-se ler na matéria, as seguintes reflexões sobre o modelo chileno de educação, enfatizadas pelo então presidente da Comissão de Educação do Senado, o político Jaime Quintana, do Partido pela Democracia (PPD):

Esse assunto acabou colocando sobre a mesa a discussão sobre o modelo chileno de educação. Teremos de decidir se realmente queremos um modelo de educação pública de qualidade ou se estamos fazendo as coisas de modo a permitir que o mercado entre por todos os lados (CHARLEAUX, 2011b).

A situação piorou quando o governo chileno foi citado por ter se deixado corromper por empresas privadas que, neste caso, visam veicular mensagens publicitárias nos livros didáticos do Chile, afirmou Charleaux (2011b) coloca que desde que o governo atual chileno assumiu o poder, enfrenta denúncias de ligações irregulares entre o presidente Sebastián Piñera e diversas empresas privadas, para justificar a publicidade nos livros didáticos do Chile.

Infelizmente atitudes como essas, tomadas por representantes de Estado põe em evidência a necessidade de se repensar nas imagens colocadas nos livros didáticos. Sobre essa questão, Tonini (2011) coloca que é necessário

Examinar a imagem veiculada nos livros didáticos de Geografia como produtora de significados, que utiliza diversas estratégias implicadas em relações de poder para tecer uma malha privilegiada para determinados conhecimentos, é entender que o significado não existe no mundo, não é encontrado como elemento da natureza, como algo que está vagando, o qual, basta pagarmos para colocar sobre as coisas, sobre os objetos que está (TONINI, 2011, p. 153).

Além desta autora, muitos outros estudos sobre a imagem e o uso dos livros didáticos apontam a necessidade da inserção de uma cultura visual nas práticas pedagógicas escolares que não se resuma somente a ver o que é a imagem, mas, acima de tudo, o que ela quer nos dizer, colocando em pauta a questão da subjetividade de quem a vê. Desta maneira, as prá- 
ticas pedagógicas colocarão os estudantes a se posicionarem como protagonistas, estabelecendo relações e associações com outras imagens, leituras e reflexões a partir da subjetividade, na qual o seu cotidiano está inserido.

Sobre a publicidade e sua influência na vida dos jovens, o IDEC (2002, p. 18) afirma que "As crianças e os jovens são geralmente muito vulneráveis à publicidade, porque não têm uma mentalidade crítica nem a capacidade de ler a verdadeira mensagem que uma determinada publicidade está transmitindo".

Dentro dessa perspectiva, não podemos esquecer que a escola tem papel importante, pois ela deve ser compreendida como um espaço apropriado para o desenvolvimento cognitivo que, ao acolher crianças e jovens, torna proveitoso o desenvolvimento das potencialidades desses sujeitos, cujo objetivo é formar pessoas interativas, co-participes no processo educacional e capazes de entenderem as mensagens veiculadas pela mídia e diferentes meios de comunicação, tornando-os sujeitos conscientes e capazes de interagirem melhor com o que o mundo lhes oferece por meio da publicidade e propaganda, sendo mediados pelo professor, embora o aluno seja:

[...] o maior responsável pela construção de seu desenvolvimento. Ele vai gradativamente construindo a si próprio. À medida que se elevam em suas faixas etárias, a linguagem vai ganhando um tom mais abstrato. Contudo, as pessoas mais afeitas ao aprendizado além do aluno, como principalmente, o professor, podem e devem contribuir para criar condições para tal. Elas precisam identificar esse ritmo e inferir sobre essas potencialidades, para estimular o alcance do que o aluno deve internalizar (TAVARES, 2008, p. 100).

Assim, é papel da escola promover o ensino e a aprendizagem a partir dos diferentes meios de comunicação, levando os educandos a perceberem que a aprendizagem se constrói na interação com outros sujeitos, cabendo à escola:

[...] atuar no sentido de transformar os meios de comunicação em aliados do processo educativo dos alunos [...]. Se for bem-sucedida, despertará a consciência crítica dos alunos-espectadores com o intuito de torná-los agentes da comunicação (IDEC, 2002, p. 31).

Deste modo, cabe ao professor promover um planejamento pedagógico que viabilize um ensino e aprendizagem que permita utilizar as informações disponíveis pela mídia, pela propaganda na TV e nos rádios, jornais, 196 Número temático: Desenho e Educação: Cultura Visual e Cidade. A Cor das Letras - UEFS, n. 
pelos out doors dispersos nos mais variados lugares e vias da cidade, pelo cinema, pela música e, também, pelo livro didático, explorando efetivamente as mensagens que as imagens impressas neles querem nos dizer.

\section{CONSIDERAÇÕES FINAIS}

Não podemos negar que a imagem tem um espaço privilegiado no contexto atual que vivemos, pois ela é capturada pelo nosso campo visual e nos faz, muitas vezes, agir de acordo com a mensagem que ela traz, sem uma reflexão prévia.

Ao mesmo tempo em que não se discute a importância do lugar que a imagem ocupa em nossas vidas, percebe-se o quanto elas são exploradas de modo errôneo, ou pouco produtivo em alguns âmbitos, sobretudo nos espaços escolares.

Nos livros didáticos, o uso das imagens estimulou e continua a estimular os educandos e educadores nas práticas pedagógicas, chegando até mesmo a ser considerado um processo de "alfabetização visual", com o intuito de, cada vez mais, gerar uma melhor compreensão e apreensão dos conteúdos trabalhados de forma mais significativa, enfática e eficaz. Por isso, buscamos uma análise crítico-reflexiva das imagens publicitárias utilizadas pelos autores Valquíria Pires e Beluce Belucci, no módulo 5 do livro didático de Geografia do Projeto Radix, do 8 o ano do Ensino Fundamental, da editora Scipione, por entendermos que se faz necessário uma reflexão mais apurada dessas imagens dentro do contexto de ensino e de aprendizagem, na perspectiva de formarmos sujeitos conscientes de seus papéis na sociedade atual, ora discutido no decorrer deste artigo.

Em contrapartida, percebemos na busca por outros exemplos, que no Chile, há fortes embates por conta do uso de mensagens/imagens publicitárias nos livros didáticos do país, por conta de muitos teóricos compreenderem tal prática como sendo estímulo ao consumismo desenfreado; à educação como negócio.

Imaginamos que o uso das imagens/mensagens publicitárias nos livros didáticos, de Geografia ou não, não deva ser considerada um problema, desde que, seja mediada pelos educadores, no sentido de explicitar suas reais pretensões didáticas. Utilizar-se de tais recursos, na formação de alunos críticos e atuantes deveria ser (se ainda não é), o papel do uso das imagens/mensagens publicitárias nos livros didáticos. 


\section{REFERÊNCIAS}

BACCEGA, Maria Aparecida; FREIRE, Denise de Oliveira. A publicidade nos livros didáticos do Ensino Médio. Comunicação \& Educação, ano XII, n. 2, maio/ago. 2007.

CASTELLAR, Sônia Vanzella. A cartografia e a construção do conhecimento em contexto escolar. In: ALMEIDA, Rosângela Doin. Novos Rumos da cartografia escolar: currículo, linguagem e tecnologia. São Paulo: Contexto, 2011.

CHARLEAUX, João Paulo. Chile põe publicidade em livro didático. Disponível em: http://www.estadao.com.br/estadaodehoje/20110410/not_imp704193,0.php. Acesso em 10 de abr. 2011a.

CHARLEAUX, João Paulo. Fica claro que a educação chilena é um negócio, afirma deputada chilena. Disponível em: http://www.estadao.com.br/noticias/vidae,\%E2\%80\%98fica-claroque-a-educacao-e-um-negocio--afirma-deputada-chilena,704727,0.htm. Acesso em 11 de abr. $2011 b$.

DURAND, Gilbert. O imaginário. São Paulo: Difel, 1998.

DURANDIN, Guy. As mentiras na propaganda e na publicidade. São Paulo: JSN Ed., 1997.

IDEC. Publicidade e Consumo - Coleção Educação para o Consumo Responsável. São Paulo: Idec, 2002.

JOLY, Martine. Introdução à análise da imagem. Campinas: Papirus, 1996.

PAZ, Otávio. O arco e a lira. Rio de janeiro: Nova fronteira, 1982.

PIRES, Valquíria; BELUCCI, Beluce. Geografia. Projeto Radix. Módulo 5. 8o Ano. São Paulo: Scipione, 2009.

SANDMANN, Antônio José. A linguagem da propaganda. 6. ed. São Paulo: Contexto, 2001.

TAVARES, Mauro Calixta. Reflexões sobre a escola. Curitiba: Juruá, 2008.

TONINI, Ivaine Maria. Livro didático: textualizações em rede? In: TONINI, Ivaine Maria et al. (Org.). O ensino de geografia e suas composições curriculares. Porto Alegre: UFRGS, 2011.

198 Número temático: Desenho e Educação: Cultura Visual e Cidade. A Cor das Letras - UEFS, n. 